\title{
Corrigendum: Number-induced shifts in spatial attention: a replication study
}

\author{
Kiki Zanolie ${ }^{1,2 *}$ and Diane Pecher ${ }^{1}$ \\ Department of Psychology, Erasmus University Rotterdam, Rotterdam, Netherlands \\ 2 Institute of Psychology, Leiden University, Leiden, Netherlands \\ *Correspondence: c.k.k.zanolie@fsw.leidenuniv.nl
}

Edited and reviewed by:

Andriy Myachykov, Northumbria University, UK

Keywords: corrigendum, Figure 1, placeholders, digit display, missing placeholders

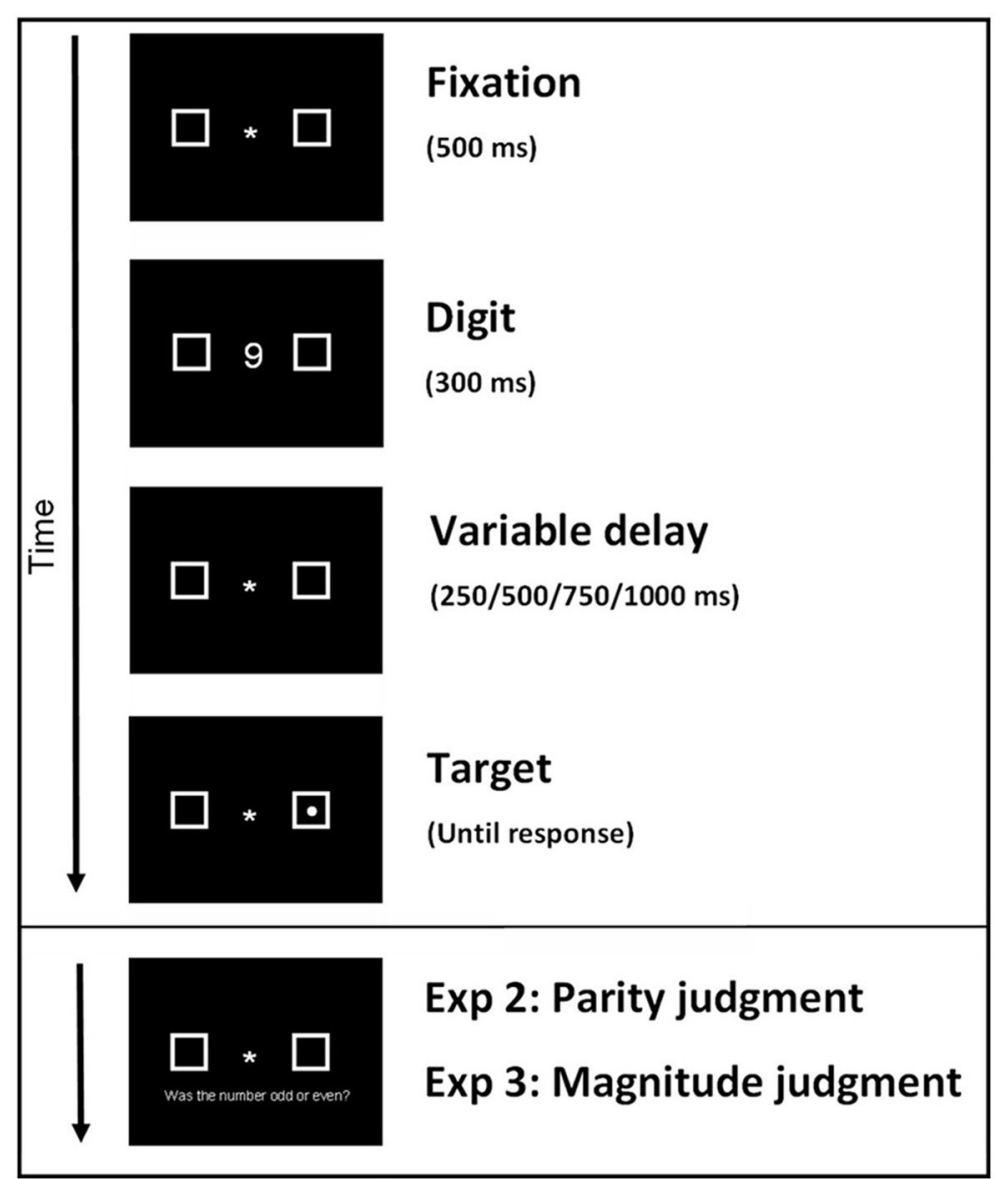

FIGURE 1 | The trial sequencestarted with a $500 \mathrm{~ms}$ fixation cross, followed by a $300 \mathrm{~ms}$ digit $(1,2,8,9)$ display, and a variable delay of $\mathbf{2 5 0}, \mathbf{5 0 0}, \mathbf{7 5 0}$, or $\mathbf{1 0 0 0} \mathrm{ms}$. Then a target was presented randomly in one of the two place holders on $80 \%$ of all trials. Participants had to respond as fast as possible by pressing the space bar when they detected the target. In Experiment 2 and 3 a delay of $200 \mathrm{~ms}$ (as the variable delay) was presented after which participants decided whether the previously seen digit was odd or even (Experiment 2 and Replication Experiment 2) or whether the digit was higher or lower than 5 (Experiment 3 and Replication Experiment 3). Underneath the parity or magnitude question the response options with corresponding keys " $z$ " and " $x$ " where displayed.
A corrigendum on

Number-induced shifts in spatial attention: a replication study by Zanolie, K., and Pecher, D. (2014). Front. Psychol. 5:987. doi: 10.3389/fpsyg.2014.00987

This is a corrigendum for NumberInduced Shifts in Spatial Attention: A Replication Study.

Figure 1 of the manuscript does not completely represent the exact configuration of the experiments, such that the Display of the Digit should also hold two placeholders as in all the other Displays (Fixation, Variable delay, Target and Parity/Magnitude judgment). This is a subtle but critical difference.

Conflict of Interest Statement: The authors declare that the research was conducted in the absence of any commercial or financial relationships that could be construed as a potential conflict of interest.

Received: 26 September 2014; accepted: 06 October 2014; published online: 27 October 2014.

Citation: Zanolie K and Pecher D (2014) Corrigendum: Number-induced shifts in spatial attention: a replication study. Front. Psychol. 5:1206. doi: 10.3389/fpsyg. 2014.01206

This article was submitted to Cognition, a section of the journal Frontiers in Psychology.

Copyright (๑) 2014 Zanolie and Pecher. This is an openaccess article distributed under the terms of the Creative Commons Attribution License (CC BY). The use, distribution or reproduction in other forums is permitted, provided the original author(s) or licensor are credited and that the original publication in this journal is cited, in accordance with accepted academic practice. No use, distribution or reproduction is permitted which does not comply with these terms. 